SESSION IV

COMMUNICATIONS LIBRES ET RAPPORT DES GROUPES DE TRAVAIL

\title{
Proteins of the milk and genetic variants in certain sheep populations of Sicily (Barbaresca-Siciliana)
}

L. CHIOFALO and P. MICARI

Institute of Zootechny, Faculty of Veterinary Science, University of Messina, Italy

After giving information on the origins and the breeding of the Barbaresca-Sicilian sheep, the authors refer the results of an electrophoretic assay ( $\mathrm{pH} 8.6$ starch gel) on the individual milk of 200 subjects chosen by chance in diverse districts of Sicily.

Proteins of the whey : the pathways present one single constant band of $\beta$-lactoglobulin, whereas for the $\alpha$-lactoalbumin there were band $A$ and the variant with a genic frequency of 0.5 p. 100 of the B allele. Caseins : the most common result is 3 bands in the $\alpha_{s}-C n$ zone and 2 bands in the $\beta$-Cn zone. It is also possible to observe 2 ( 20 subjects) and 4 ( 2 subjects) bands in the $\alpha_{s}$ zone and 3 bands (22 subjects) in the $\beta$-Cn zone.

In the conclusions the authors underline the possibility of utilizing the obtained data in the selection of the considered race-population which, as is well-known, is bred for the production of milk and meat.

\section{Frequencies of some B blood group alleles in laying hens from a selection and crossbreeding experiment}

\author{
I. EDFORS-LILJA *, C. WEYDE *, B. GAHNE *, L.E. LILJEDAHL * \\ and M. SIMONSEN ** \\ * Dept of Animal Breeding and Genetics, Swedish University of Agricultural Science, \\ S-750 07 Uppsala, Sweden \\ ** Dept of Experimental Immunology, University of Copenhagen \\ Nerre Allé 71, DK-2100 Copenhagen, Denmark
}

The frequencies of four $B$ blood group alleles $\left(B^{15}, B^{15}, B^{19}\right.$ and $\left.B^{21}\right)$ were studied in a 647 hens and 214 cocks obtained from a Scandinavian selection and crossbreeding experiment. The lines were selected for number of eggs, egg weight and for egg weight and egg number combined into a selection index, respectively. The selection lines differed from the control line with regard to $B$ allele frequencies. Some associations were found between the different $B$ alleles and production traits such as age at first egg, number of eggs, egg mass and rate of lay. 